\title{
Analysis of Raman Spectroscopy and SEM of Carbon Nanotubes Obtain by CVD
}

\author{
L. Béjar ${ }^{1}$, Abraham A. Mejía $^{2}$ C. Parra $^{3}$, C. Aguilar ${ }^{4}$, A. Medina ${ }^{1}$, S E. Borjas-García ${ }^{1}$, J. L. Bernal ${ }^{5}$
}

1. UMSNH. Ciudad Universitaria. Morelia, Michoacán, México.

2. Alumno Doctorado Posgrado de la Facultad de Ingeniería Mecánica, Universidad Michoacana de San

Nicolás de Hidalgo, Ciudad Universitaria, Michoacán, México

3. Departamento de Física, Universidad Técnica Federico Santa María, Valparaíso, Chile.

4. Departamento de Ingeniería Metalúrgica y Materiales, Universidad Técnica Federico Santa María, Valparaíso, Chile

5. Departamento de Ingeniería Mecánica, Instituto Tecnológico de Orizaba, Veracruz México

Currently, carbon nanotubes are widely used with different precursors, methods for different applications causing a boom in metal alloys for biomedical applications. [1-2] The objective of this work is to verify if the titanium of high purity and titanium at $600^{\circ} \mathrm{C}$ treated thermally, can be used as catalysts to obtain carbon nanotubes by the CVD method. We use as a catalyst the cobalt and iron, for both cases Ti high purity and $\mathrm{Ti}$ at $600^{\circ} \mathrm{C}$, placed in an agate mortar for mixing and then in an alumina crucible to catalyze at $600^{\circ} \mathrm{C}$, then it is placed in a tube of quartz of 4 inches $\varnothing(101.6 \mathrm{~mm})$ by 39.37 inches $(0.0393 \mathrm{~mm})$. The oven to use model. TFM2-1200, in which $500 \mathrm{~L} / \mathrm{min}$ of Ar is supplied for 11 minutes at a temperature of $730^{\circ} \mathrm{C}$, which is maintained for 30 minutes, with a flow of $100 \mathrm{~L} / \mathrm{min}$ of ethylene and $500 \mathrm{~L} / \mathrm{min}$ of Ar Subsequently the supply of $\mathrm{C}_{2} \mathrm{H}_{4}$ is closed and the Ar is lowered to 300 $\mathrm{L} /$ min for 120 minutes until reaching $25^{\circ} \mathrm{C}$. Raman spectroscopy performed in an Invia Reflex Raman Microscope (RENISHAW) with Resonsac $785 \mathrm{~nm}$ laser diode, Ion Ar 514nm laser, a resolution obtained approximately $1 \mathrm{~cm}^{-1}$; to verify the possible existence of obtaining carbon nanotubes by means of the CVD method. Raman spectroscopy. It establishes a range of tangential mode $\mathrm{G}$ around $1590 \mathrm{~cm}^{-1}$ which were used to identify the presence of carbon ordered as graphite and carbon nanotubes, having hybridized the carbon system. The D band around $1350 \mathrm{~cm}^{-1}$ is associated with defects or amorphous carbon, giving an indication of the amount of disordered carbon. Therefore, the ratio of the $\mathrm{D} / \mathrm{G}$ band intensities is used as a qualitative measurement for the formation of unwanted forms of carbon [3-5]. Figure 1. Presents the following peaks indicating the presence of carbon nanotubes, (a) $1344.82 \mathrm{~cm}-1$, 997.71u.a. (b) $1588.35 \mathrm{~cm}^{-1}, 358.97$ u.a. (c) $1341.98 \mathrm{~cm}^{-1}, 587.66$ u.a. (d) $1581.23 \mathrm{~cm}^{-1}, 819.48$ u.a. In the spectroscopy (B) figure 1 of the Ti at $600^{\circ} \mathrm{C}$ presents the following peaks (e) $1349.47 \mathrm{~cm}^{-1} 189.29$ u.a. (f) $1586.16 \mathrm{~cm}^{-1}$, 198.18u.a. (g) $1343.79 \mathrm{~cm}^{-1}, 302.44$ u.a. (h) $1578.74 \mathrm{~cm}^{-1}$, 369.26u.a. resulting carbon nanotubes. The micrographs realized with (SEM) Electronic Scanning Microscope model EVO MA 10. The morphology showing agglomeration with different diameters and lengths was observed presenting a complex length measurement, for Ti at $600^{\circ} \mathrm{C}$ figure 2 (a) and (b). In figures (c) and (d) although there is agglomeration, a better result can be obtained with $\mathrm{Ti}$ of high purity, to obtain carbon nanotubes. In conclusion, we can say those metallic elements are proposed to sinter carbon nanotubes by the CVD method. Which offers a simple, innovative and effective procedure.

\section{References:}

[1] Jong-Hee Park, "Chemical Vapor Deposition”, Scarborough, ON, Canada p. 1-22, 2001.

[2] Wesley F. Oliveira, Isabel R.S. Arruda, Germana M.M. Silva, Materials Science \& Engineering C 81 (2017), p. 597.

[3] Dresselhaus, M. S. et al, Contemporary Concepts of Condensed Matter Science 3 (2008), p. 83. 
[4] Bachilo, S. M. et al, Science, 298(5602) (2002), p. 2361.

[5] Bergstrom Jr, R., \& Knoesel, E., Bulletin of the American Physical Society, 52 (2007).
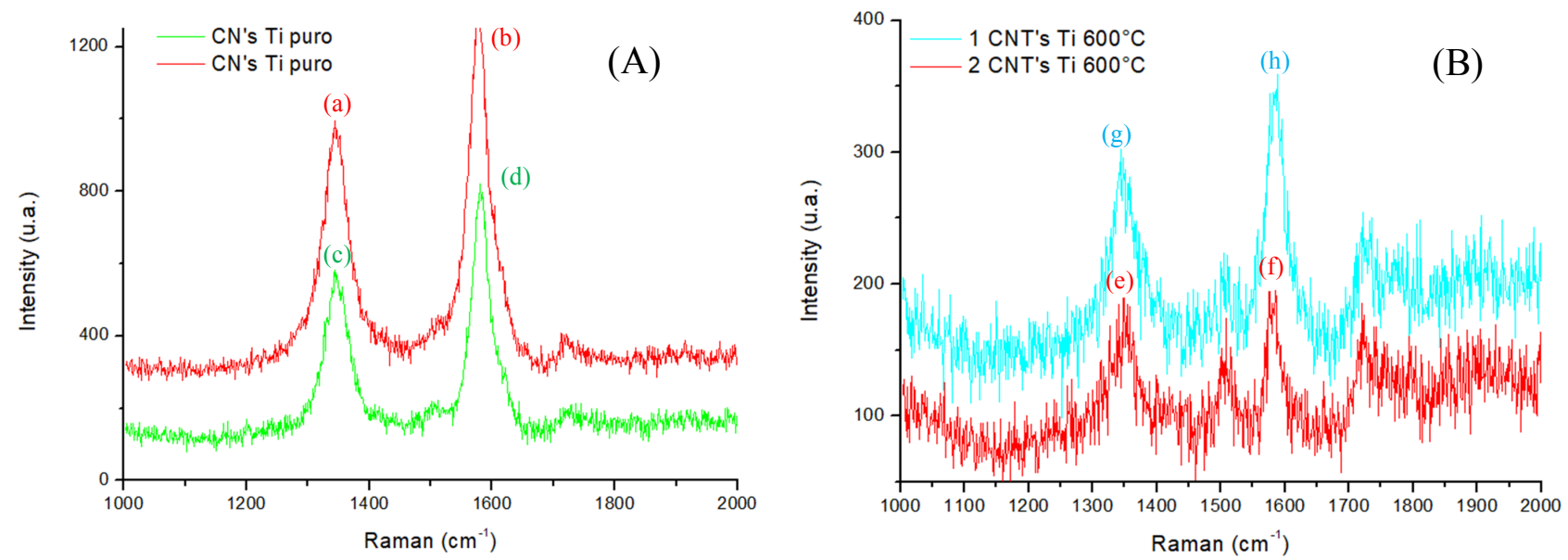

Figure 1. Spectroscopic Raman (a) Titanium de high purity (b) Titanium a $600^{\circ} \mathrm{C}$.

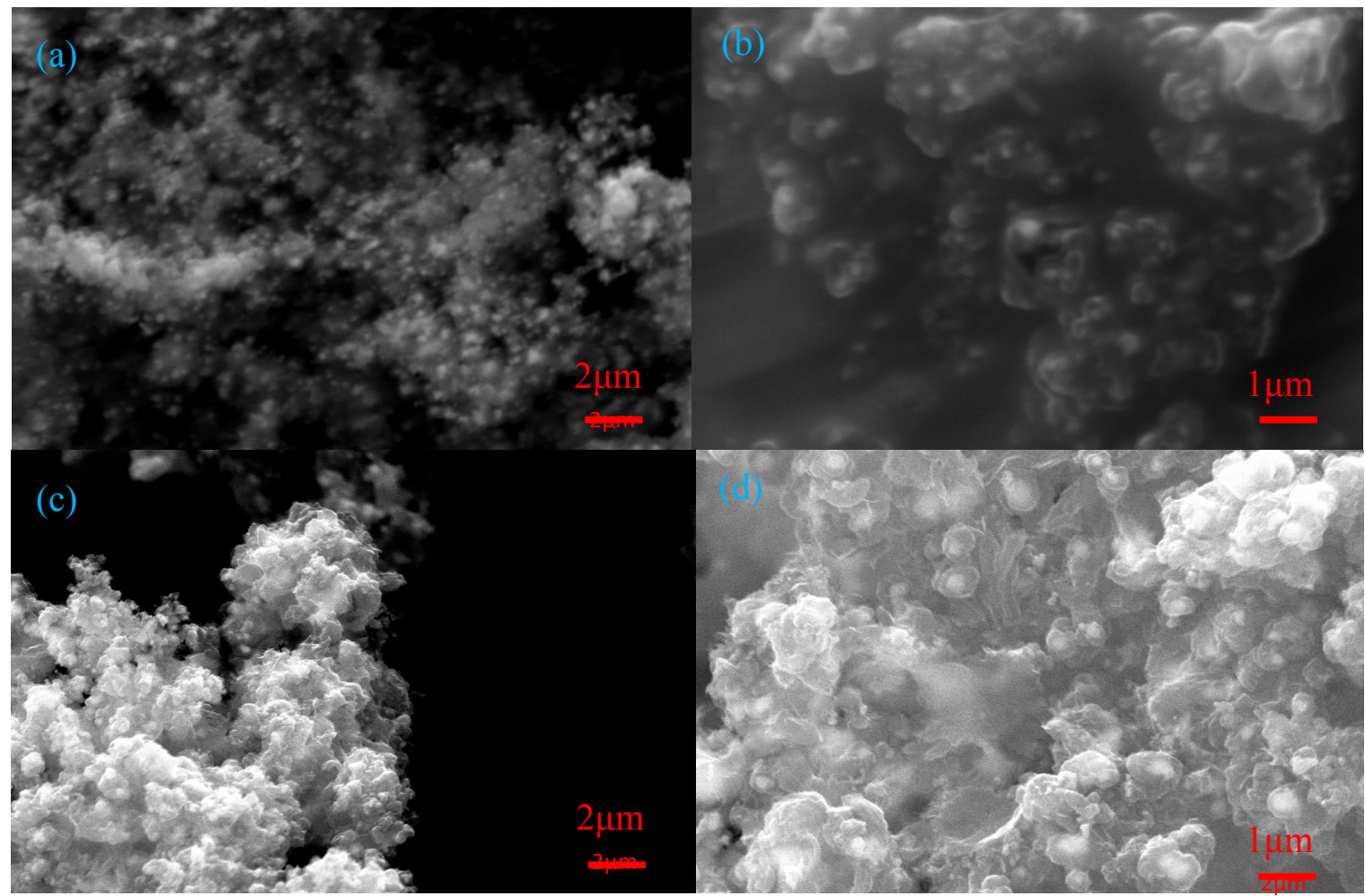

Figure 2. Micrographs (a) magnification at $5 \mathrm{kX}$ (b) Magnification at $10 \mathrm{kX}$ of $\mathrm{Ti}$ at $600^{\circ} \mathrm{C}$, (c) magnification at $5 \mathrm{kX}(\mathrm{d})$ Magnification at $10 \mathrm{kX}$ of Ti high purity. 